\title{
Perception of Patients on the Influence of Doctor- Patient Relationship on Effective Healthcare Delivery in Some Health Facilities in Ogbia Local Government Area of Bayelsa State, Nigeria
}

\author{
Boloya Vukumo Eric ${ }^{1}$, Tawari Erebi Patricia ${ }^{1}$ \\ ${ }^{1}$ Department of Chemical Pathology, Faculty of Basic Medical Sciences, College of Health Science, \\ Niger Delta University, Bayelsa State, Nigeria \\ Corresponding Author: Tawari Erebi Patricia
}

\begin{abstract}
Background: There is a deep dissatisfaction towards the services offered by doctors in government hospitals. Communication, being one of the major issues both on the part of the doctor and patient. There are also instances where patients lie to doctors about their health status, probably because the doctor fails to create a safe and conducive environment for the patient or because the patient could not confide in the doctor thus resulting in ineffective treatment. The quality of relationship between doctors and patients in government hospitals is fundamental for the several outcomes as regard services rendered by the doctor and those received by the patients and in other to improve the quality of healthcare delivery in public health care sector, there is the need for a research in the possible causes and solution to these problems. The study aimed to determine the perceived influence of doctor-patient relationship on effective health care delivery in some Health Facilities in Ogbia Local Government Area of Bayelsa State.

Methods: A descriptive cross-sectional study design was conducted among patients in Federal Medical Center, Otuoke, General Hospital, Kolo and Cottage Hospital, Otuasega, all in Ogbia Local Government Area of Bayelsa state. Data collection was carried out using both selfadministered and interview administered questionnaire. 138 patients were selected for the study. An average of 20 interviews was conducted per clinic day.
\end{abstract}

Results: Results of the study showed that majority of patients interviewed agreed that their relationship with the doctor is important in treatment outcome and were involved in making treatment decisions and were satisfied with the services received from their doctors.

Conclusion: Many of the patients were satisfied with the level of doctor patient relationship.

Key words: Perception, Doctor- Patient relationship, Health care delivery.

\section{INTRODUCTION}

The doctor-patient relationship has been defined as a consensual relationship in which the patient knowingly seeks the physician's assistance and in which the physician knowingly accepts the person as a patient. At its core, the doctor-patient relationship represents a fiduciary relationship in which by entering the relationship, the physician agrees to respect the patients' autonomy, maintain confidentiality, explain treatment options, obtain informed consent and provide the highest standard of care (Dwolatzky et al., 2006).

The importance of a cordial relationship between patient and physician can never be overemphasized because in most cases an accurate diagnosis, as well as an effective treatment, relies directly on the quality of this relationship. To attend to those who suffer, a physician must possess 
not only the scientific knowledge and technical abilities, but also an understanding of human nature. The patient is not just a group of symptoms, damaged organs and altered emotions. The patient is a human being, at the same time worried and hopeful, who is searching for relief, help and trust (Helin, 2002; Curran 2007).

Generally, there is a deep dissatisfaction of patients towards the services offered by doctors in Government Hospitals. There have been some complaints about doctor-patient relationship in Federal Medical Center, Otuoke. Communication being one of the major issues, both on the part of the doctor and the patient. Most complaints about doctors are related to issues of communication, not clinical competency. Patients want doctors who can skilfully diagnose and treat their sicknesses as well as communicate with them effectively (Goold, 1999; Kelley et al., 2014). There are instances where patients lie to doctors about their health status, probably because the doctor failed to create a safe and conducive environment for the patient, or because the patient could not confide in the doctor, thus resulting in ineffective treatment (i.e. non holistic care). Also, some patients complain of doctors who do not pay attention to them. They say the doctor finishes writing his prescription before they start talking. Some doctors have also been said to lack empathy towards patients. They lack the intellectual ability to identify some of the thoughts, feelings or state of the patient (Lee, 2002).

The quality of relationship between doctors and patients in Government hospitals is foundational for the several outcomes as regards services rendered by doctors and those received by patients. But not much work has been done on doctorpatient relationship in Nigeria compared to other parts of the world. In order to improve the quality of health care delivery in the public health sector, there is the need for a research on the possible causes and solutions to this problem. This study aimed to determine the perceived influence of doctor-patient relationship on effective health care delivery in some Health Facilities in Ogbia Local Government Area of Bayelsa State.

\section{METHODOLOGY \\ Study Area}

This study was carried out in Ogbia local government area of Bayelsa state of Nigeria (south of Nigeria) in West Africa. Ogbia Town is the Headquarter of Ogbia Local Government Area in Bayelsa state. The Local Government Area has an average land area of $695 \mathrm{~km}^{2}$ and a total population of 266,008 as at 2016. English is the official language, but the major local language spoken is the Ogbia Language.

Public health facilities in Ogbia include Federal Medical Center, Otuoke, General Hospital, Kolo, Cottage Hospital, Otuasega.

\section{Study Design}

A descriptive cross-sectional study design was used to determine the influence of doctor-patient relationship on effective health care delivery in the various tertiary facilities mentioned above. A simple random sampling technique by balloting method was utilized. Patients were selected at random giving every individual an equal opportunity of being selected. The study area was structured into clinics in the various departments: Pediatrics, Obstetrics and Gynecology, Internal medicine and surgery. A set of questionnaires was distributed to Patients who attend clinics in the various departments listed above while another set was distributed to doctors.

\section{Study Duration}

The study was carried out over a period of 3 months, consisting of time to be spent on obtaining approval, data collection, collation, analysis and report writing.

\section{Study Population}

This comprised of different categories of patients in the different public Health facilities in Ogbia.

\section{Inclusion Criteria}

Patients (care recipients) who attend the various clinics, patient carers (both those 
who would respond on behalf of the patients and also those who are "potential patients" and may have had previous experiences with doctors).

\section{Exclusion criteria}

Patients who do not attend the various clinics

\section{Sample Size Determination}

Step 1: When population is greater than 10,000

$\mathrm{n}=\frac{Z^{2} p q}{d^{2}}$

$\mathrm{n}=$ sample size

$\mathrm{Z}=$ critical value at $95 \%$ confidence level, usually 1.96

$\mathrm{p}=$ Prevalence $(90 \%)$

$\mathrm{q}=1-\mathrm{p}(1-0.90)=0.10$

$\mathrm{d}=$ Precision, usually $5 \%$. Nonresponse rate $=10 \%$

$\mathrm{n}=1.96^{2} \times 0.90 \times 0.10 / 0.05^{2}$

$\mathrm{n}=138$

\section{Data Collection}

\section{Instrument for Data Collection:}

Semi-structured questionnaires were used to collect information on respondent's perception on the influence of doctor-patient relationship on effective healthcare delivery in Federal Medical Center, Otuoke. The questionnaires were in two forms, selfadministered and the interviewer based.

\section{Ethical Consideration}

Ethical approval for the conduct of the study was obtained from the Research and Ethics Committee of various Health Facilities respectively before commencement.

At the various clinics, verbal consent was obtained from the patients. Also, confidentiality of respondents was assured while getting their consent before recruiting them for the study.

\section{RESULTS}

The total number of questionnaires administered was 140 . Response rate was $99.5 \%$. Out of 140 questionnaires distributed, 138 were retrieved, entered and analyzed. Tables were used to represent the results from the data analysis.
Table 1 shows the Sociodemographics Profile of patients. Mean age of the patients used in the study was 30.4 years, $54.2 \%$ of the patients were within the age range of 21-30years, the percentage of females were greater than males $(51.4 \%)$, 98.6\% were Christians and $44.9 \%$ were civil servant, while $67.4 \%$ of them had tertiary level of education.

Table 1: Patient's Socio-demographics

\begin{tabular}{|c|c|c|}
\hline & $\begin{array}{l}\text { FREQUENCY } \\
n=138\end{array}$ & $\begin{array}{l}\text { PERCENTAGE } \\
\%\end{array}$ \\
\hline \multicolumn{3}{|l|}{ Age } \\
\hline $10-20$ & 10 & 7.3 \\
\hline $21-30$ & 74 & 54.2 \\
\hline $31-40$ & 44 & 32.1 \\
\hline $41-50$ & 9 & 6.6 \\
\hline Total & 138 & 100 \\
\hline \multicolumn{3}{|l|}{ Sex } \\
\hline Male & 67 & 48.6 \\
\hline Female & 71 & 51.4 \\
\hline Total & 138 & 100 \\
\hline \multicolumn{3}{|l|}{ Religion } \\
\hline Christianity & 136 & 98.6 \\
\hline Islam & 1 & 0.7 \\
\hline Atheist & 1 & 0.7 \\
\hline Total & 138 & 100 \\
\hline \multicolumn{3}{|l|}{ Occupation } \\
\hline Farming & 2 & 1.4 \\
\hline Fishing & 7 & 5.1 \\
\hline Trading & 26 & 18.8 \\
\hline Civil servant & 62 & 44.9 \\
\hline Others (Student) & 41 & 29.7 \\
\hline Total & 138 & 100 \\
\hline \multicolumn{3}{|c|}{ Level of education } \\
\hline Primary & 9 & 6.5 \\
\hline Secondary & 36 & 26.1 \\
\hline Tertiary & 93 & 67.4 \\
\hline Total & 138 & 100 \\
\hline
\end{tabular}

Table 2 illustrates the perception of patients on the way they were treated by their doctors. $64.5 \%$ said their doctor always obtain consent before physical examination. 133 out of 138 patients interviewed said they had no difficulty in asking their doctor questions and half of the respondents 50\% said their doctors' attitude towards them was always reassuring. $89 \quad(64.5 \%)$ respondents said their doctors listened to them attentively and until the end of their complaint while $38(24.5 \%)$ of them said their doctors are easily distracted during consultation. When asked if their doctors explain things concerning their health problems in clear and complete terms, 58 (42\%) said they always do and only 47 said their doctors always explained the treatment 
Boloya Vukumo Eric et.al. Perception of patients on the influence of doctor-patient relationship on effective healthcare delivery in some health facilities in ogbia local government area of Bayelsa state, Nigeria.

chosen. On involving them in making treatment decisions, the majority said the doctors do so only sometimes 55 (37.7\%) while $32(23.2 \%)$ said never and $127(92 \%)$ welcomed the opportunity to be more involved in making treatment decision. 133
(96.4\%) agreed that their relationship with the doctor is important in treatment outcome and when asked how they felt after consultation with their doctor, 114 (82.6\%) said they were satisfied and 128 (92.8\%) felt encouraged to go for subsequent visits.

Table 2: Perception of Patients on the way they are treated by Doctors

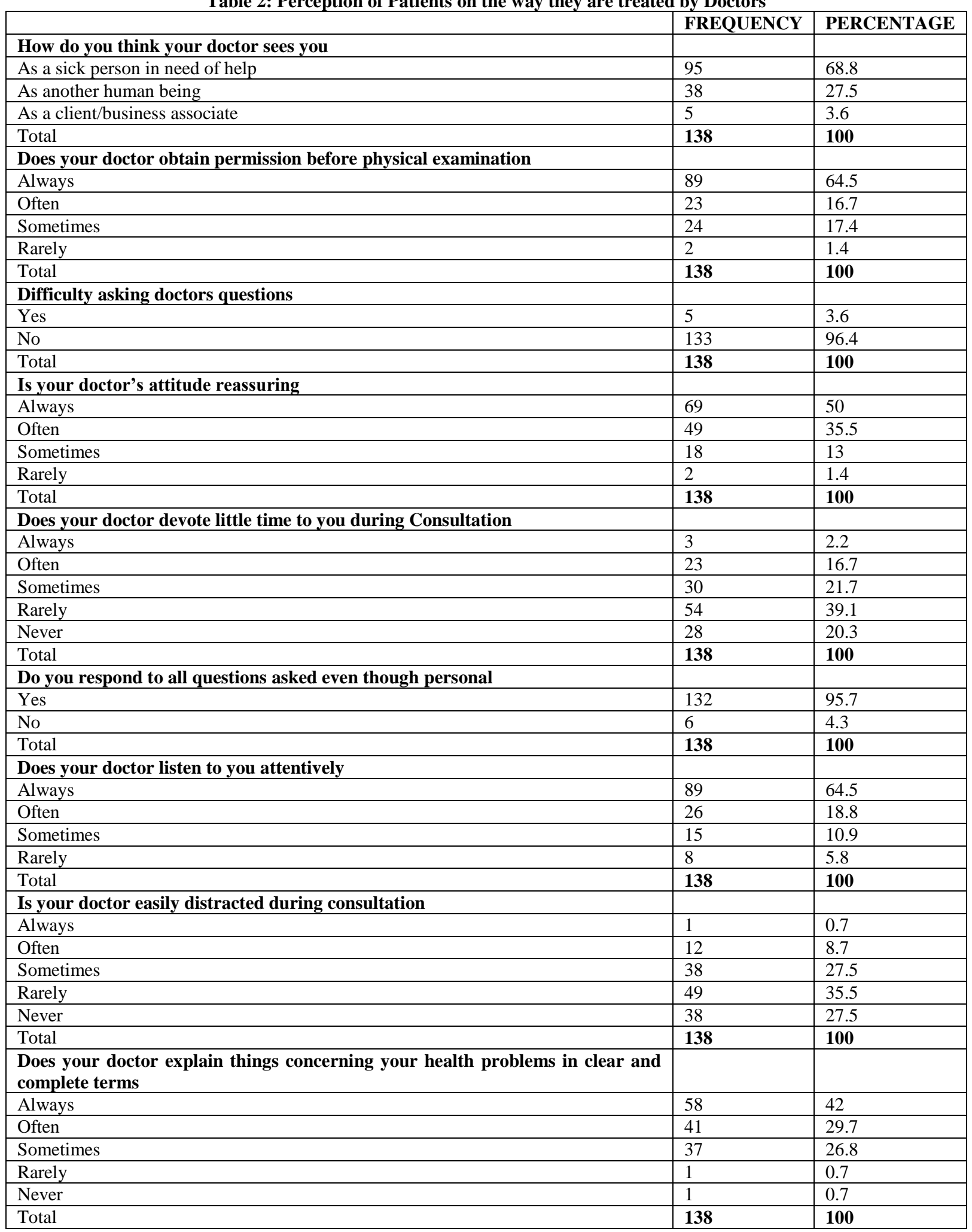


Boloya Vukumo Eric et.al. Perception of patients on the influence of doctor-patient relationship on effective healthcare delivery in some health facilities in ogbia local government area of Bayelsa state, Nigeria.

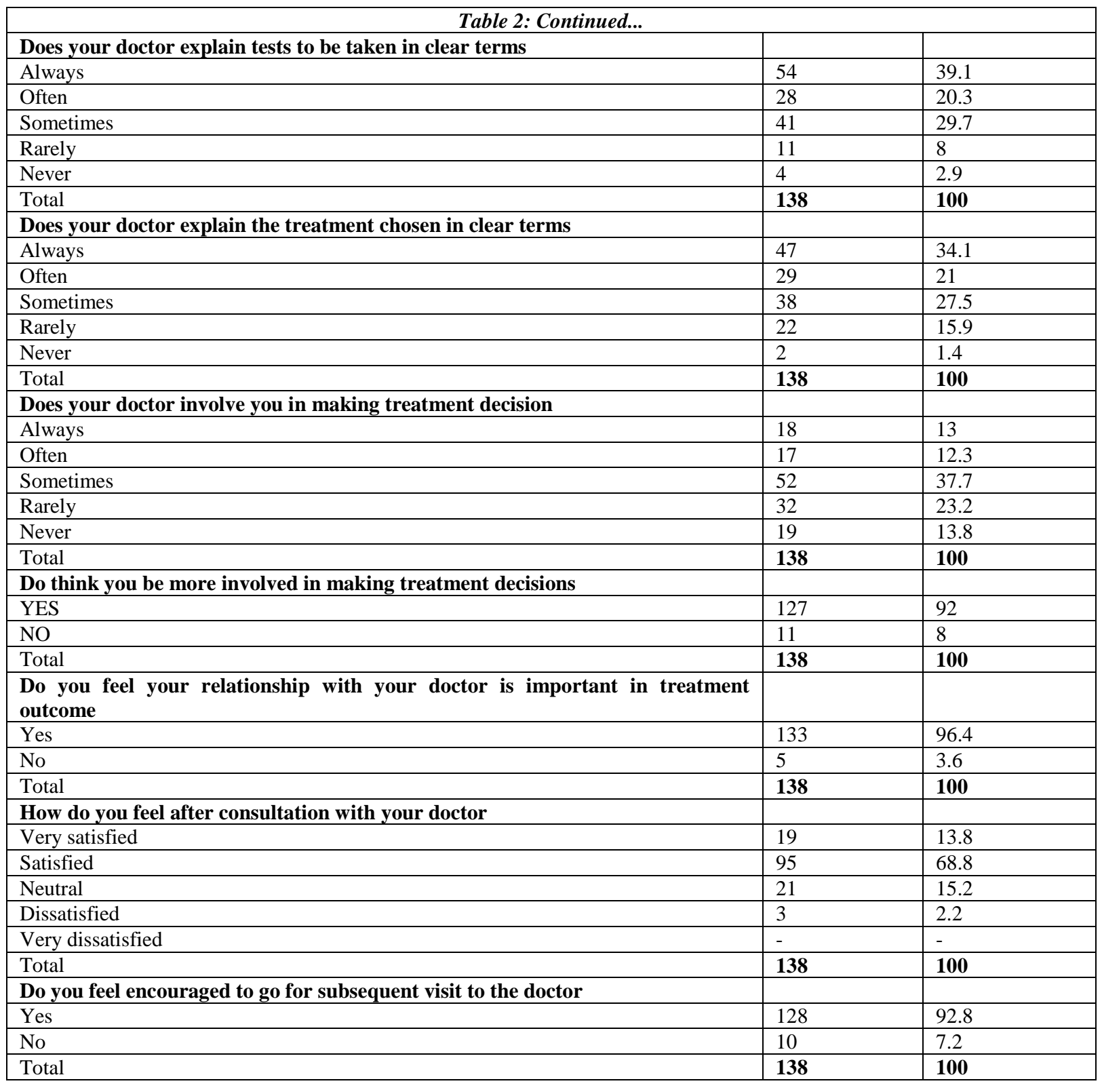

\section{DISCUSSION}

The major aim of this study was to investigate the perception of patients and its influence on Doctor- Patient relationship on effective health care delivery. Results from this study demonstrated that a greater number of patients welcomed the idea of being more involved in making treatment decision and felt satisfied after consultation with their doctors. Table 2 showed that $64.5 \%$ said their doctor always obtain consent before physical examination. 133 out of 138 patients interviewed said they had no difficulty in asking their doctor questions and half of the respondents 50\% said their doctors' attitude towards them was always reassuring. $89 \quad(64.5 \%)$ respondents said their doctors listened to them attentively and until the end of their complaint while $38(24.5 \%)$ of them said their doctors are easily distracted during consultation. When asked if their doctors explain things concerning their health problems in clear and complete terms, 58 (42\%) said they always do and only 47 said their doctors always explained the treatment chosen. On involving them in making treatment decisions, the majority said the doctors do so only sometimes 55 (37.7\%) while $32(23.2 \%)$ said never and $127(92 \%)$ welcomed the opportunity to be more involved in making treatment decision. 133 
(96.4\%) agreed that their relationship with the doctor is important in treatment outcome and when asked how they felt after consultation with their doctor, $114(82.6 \%)$ said they were satisfied and $128(92.8 \%)$ felt encouraged to go for subsequent visits.

Results from this study were not in total agreements with studies conducted in Port Harcourt Teaching Hospital on the perception of patients on doctor-patient relationship in the Otorhinolaryngology clinic (Onotai and Ibekwe, 2012). A descriptive study was done, duration of the field work of two weeks. The study population consisted of adult patients who attended the Otorhinolaryngology clinics. Data collection was carried out using interviewer administered semi-structured questionnaire. Results showed that majority $(95 \%)$ of patients treatment was determined by doctors. Majority of the patients $(87.5 \%)$ welcomed the opportunity to have more involvement in making treatment decisions. Most of the patients (67.5\%) were not satisfied with the services received from their doctors. In conclusion, this study showed/established Paternalistic model as the dominant pattern of doctor-patient relationship in the UPTH Otorhinolaryngology clinics. The patients preferred a more cordial relationship.

However results from our study was in concordance with another study carried in Ghana on assessing experience and perception of patients about outpatient services was carried out in Tamale teaching hospital in Ghana. The outpatient department was chosen because patients define the satisfaction experienced at this section of the hospital to be the overall output of the hospital. So, discontent of services received at this facility is a judgment on the quality of care provided by the hospital. The study findings suggested that maximum number of respondents had very good experience in relation to the nurse's respectful treatment for patients, the lighting system of the hospital and cleanliness of the environment (Yakubu et al., 2019)

\section{CONCLUSION}

A good doctor-patient relationship with good communication is a panacea for an improved health care. From the study in the selected health facilities, it was observed that many patients were satisfied with the level of doctor patient relationship in Ogbia Local Government Area in Bayelsa State.

\section{Acknowledgement: None}

\section{Conflict of Interest: None}

\section{Source of Funding: None}

\section{Ethical Approval: Approved}

\section{REFERENCES}

1. Curran, James (1 November 2007). "The Doctor, his Patient and the Illness". BMJ. 335 (7626): 941.2-941. doi:10.1136/bmj.39384.467928.94. ISSN 0959-8138. PMC 2048858.

2. Dwolatzky, T., Dwolatzky, Clarfield, A. M., \& Clarfield. (2006). Doctor-Patient Relationships. In R. Schulz, Encyclopedia of aging (4th ed.). Springer Publishing Company.

3. Goold, Susan Dorr; Lipkin, Mack (1 January 1999). The Doctor-Patient Relationship. Journal of General Internal Medicine. 14 (Suppl 1): S26-S33.

4. Helin $T$ (2002). The Physician-Patient relationship; recent development and changes. Hemophilia, 8 (2002), pp. 450-454

5. Kelley JM, Kraft-Todd G, Schapira L, Kossowsky J, Riess H (2014). "The influence of the patient-clinician relationship on healthcare outcomes: a systematic review and meta-analysis of randomized controlled trials". PLOS ONE. 9 (4): e94207. doi:10.1371/journal.pone.0094207. PMC 3981763. PMID 24718585.

6. Lee, S. J., Back, A. L., Block, S. D., \& Stewart, S. K. (2002, January 1). Enhancing physician-patient communication. Retrieved from

https://www.ncbi.nlm.nih.gov/pubmed/1244 6437

7. Onotai L.O., Ibekwe U. (2012). The perception of patients on doctor-patient relationship in Otorhinolaryngology clinics 
Boloya Vukumo Eric et.al. Perception of patients on the influence of doctor-patient relationship on effective healthcare delivery in some health facilities in ogbia local government area of Bayelsa state, Nigeria.

of the University of Port-Harcourt Teaching Hospital (UPTH), Nigeria. PMJ 2012, Vol. 6, No. 1

8. Stewart, M. A. (1995, May 01). Effective physician patient communication and health outcomes: A review. Retrieved from https://www.ncbi.nlm.nih.gov/pubmed/7728 691

9. Yakubu H. yakubu., Adams Shamsu-deen Mahama., Nkacheba Amina Abu and Habiba Issah (2019). Advancement in
Bioscience and Clinical Medicine. Volume 7, Issue 1. Pp 19-26.

How to cite this article: Eric BV, Patricia TE. Perception of patients on the influence of doctor-patient relationship on effective healthcare delivery in some health facilities in ogbia local government area of Bayelsa state, Nigeria. International Journal of Science \& Healthcare Research. 2021; 6(2): 92-98. DOI: https://doi.org/10.52403/ijshr.20210418 